Quim. Nova, Vol. 25, No. 4, 548-552, 2002

\title{
DETERMINAÇÃO DE COBRE, ALUMÍNIO E FERRO EM SOLOS DERIVADOS DO BASALTO ATRAVÉS DE EXTRAÇÕES SEQÜENCIAIS
}

\author{
Antonio Carlos Saraiva da Costa \\ Departamento de Agronomia, Universidade Estadual de Maringá, Av. Colombo, 5790, Campus Universitário, 87020-900 Maringá - PR \\ Vitor de Cinque Almeida, Ervim Lenzi e Jorge Nozaki" \\ Departamento de Química, Universidade Estadual de Maringá, Av. Colombo, 5790, Campus Universitário, 87020-900 Maringá - PR
}

Recebido em 24/4/01; aceito em 14/11/01

\begin{abstract}
DETERMINATION OF COPPER, ALUMINUM, AND IRON IN BASALTIC SOILS BY SEQUENTIAL EXTRACTIONS. Copper, aluminum and iron concentrations were determined in four geochemical fractions of three different basaltic soils from the northwest region of the Parana State, Brazil. The fractions examined were the reducible manganese dioxide and amorphous iron oxide, crystaline iron oxide, organic and residual. Metal concentrations were determined in the extracts by flame atomic absorption spectrophotometry. High Fe concentrations were extracted from the crystalline iron oxide (>20\%), as well as the amorphous iron oxide $(>12 \%)$. Copper was extracted from the amorphous and crystalline iron oxides in the range 5 to $12 \%$, but low concentrations were bound to organic matter. Low concentrations of aluminum were extracted $(<8 \%)$ from the amorphous and crystaline iron oxides, and organic matter. High concentrations of aluminum were found in the residual fraction.
\end{abstract}

Keywords: sequential extractions; basaltic soils; atomic absorption spectrophotometry.

\section{INTRODUÇÃO}

Os minerais da fração argila no solo são os responsáveis pela retenção e distribuição da água, nutrientes, calor e gases. Em solos tropicais, a mineralogia é relativamente simples, sendo constituídos principalmente de caulinita, óxidos de ferro (hematita, goetita e maghemita), óxidos de alumínio (gibbsita) e menores proporções de minerais do tipo 2:1 (vermiculita). Nos óxidos de ferro, alumínio e manganês e, nas periferias das argilas silicatadas, as adsorções de íons metálicos podem ocorrer por meio da formação de ligações covalentes ou eletrostáticas com os grupos funcionais da superfície dos óxidos ${ }^{1}$. Nos argilominerais expansivos, os grupos funcionais estão presentes nos espaços octaédricos das estruturas cristalinas e, nestes sítios, supõem-se que alguns metais sejam fortemente adsorvidos como complexos de esfera interna ${ }^{2,3}$.

Os óxidos de Fe possuem grande poder de pigmentação, determinando assim a coloração de muitos solos. A capacidade de adsorção de metais por esses óxidos é proporcional aos valores de $\mathrm{pH}$. A goetita e hematita adsorvem preferencialmente os metais na seguinte ordem: $\mathrm{Cu}>\mathrm{Pb}>\mathrm{Zn}>\mathrm{Cd}>\mathrm{Co}>\mathrm{Ni}>\mathrm{Mn}$, com a troca de posições do $\mathrm{Cu}$ e $\mathrm{Pb}$ na hematita ${ }^{1}$. Em geral, os fatores mais importantes que influenciam a adsorção seletiva dos cátions em soluções são o $\mathrm{pH}$, valência, raio iônico e o ponto de carga zero (PCZ) do sólido 4 .

$\mathrm{O}$ cobre, em virtude de suas propriedades de condutividade, maleabilidade e ductibilidade, pode ser encontrado na composição de vários pigmentos, pesticidas e corantes, entre outros. É indispensável para o desenvolvimento de plantas superiores, sendo classificado como micronutriente e atua praticamente em todas as suas vias metabólicas. Em concentrações elevadas na fase trocável do solo, observam-se efeitos tóxicos nos tecidos vegetais das plantas 5 . A dinâmica do cobre em solos é complexa, sendo afetada por inúmeros fatores entre os quais a composição química, física,

\footnotetext{
*e-mail: jnozaki@cybertelecom.com.br
}

mineralógica, a quantidade de matéria orgânica e $\mathrm{pH}$ do solo ${ }^{6}$. O cobre é também o elemento que forma complexos mais fortes com os materiais húmicos do solo ${ }^{7}$, como pode ser observado em estudos de determinação de elementos-traço da matéria orgânica por extrações seqüenciais ${ }^{8}$.

A extração seqüencial de elementos-traço em solos e sedimentos é um método de especiação química destes elementos. As informações obtidas permitem avaliar a fitodisponibilidade, fitotoxicidade, dinâmica dos elementos-traço e as transformações entre as diferentes formas químicas em solos poluídos ou agriculturáveis ${ }^{9}$. A extração seqüencial tem sido aplicado ao horizonte A de solos da Costa Rica $^{10}$, solos do estado de Kansas-E.U.A ${ }^{11}$, solos calcáreos ${ }^{12}$, e latossolos vermelho-amarelo ${ }^{13,14}$. A maioria dos estudos baseia-se no método proposto por Tessier et $\mathrm{al}^{15}$, que investigou diversos sedimentos, incluindo os metais nas frações trocável (biodisponível), carbonácea, redutiveis (óxidos de Fe e Mn), orgânica e residual.

A extração seqüencial introduzida por Tessier et a ${ }^{15}$ baseava-se em extrações em cinco estágios que eram a fase solúvel em água ou trocável, associada aos carbonatos, adsorvida em óxidos de Mn e $\mathrm{Fe}$, associada com a matéria orgânica insolúvel e, finalmente, a camada de silicatos. Várias modificações foram feitas nesta metodologia nos últimos anos, como a extração seqüencial para a remoção de metais pesados especificamente adsorvidos na fração facilmente redutível de óxidos de $\mathrm{Mn}^{16}$, a extração em três estágios para a determinação de metais pesados em sedimentos ${ }^{17}$, etc.

$\mathrm{O}$ objetivo deste trabalho foi investigar as concentrações do $\mathrm{Cu}$, $\mathrm{Fe}$ e $\mathrm{Al}$ em quatro frações químicas (óxidos de ferro amorfo e cristalino, matéria orgânica e residual), de três diferentes solos da região norte do Estado do Paraná. Estes solos, derivados de rochas basálticas, são considerados excelentes para a prática agrícola, sendo conhecidos popularmente como "terra roxa". Entretanto, podem possuir uma alta capacidade de retenção de metais tóxicos em disponibilidade no meio ambiente devido as atividades antropogênicas. Estes metais podem atingir a cadeia alimentar dos organismos vivos, ou serem lixiviados, comprometendo a qualidade das águas subterrâneas ${ }^{13}$. 


\section{PARTE EXPERIMENTAL}

\section{Amostragem}

Amostras do latossolo vermelho distroférrico, neossolo e vertissolo foram coletadas em uma toposequência de solos na região de Maringá-PR. Esses solos são argilosos e com baixos teores de areia e silte, e foram coletados na camada superficial de 0 a $20 \mathrm{~cm}$ de profundidade, secos ao ar em casa de vegetação, e tamisados em peneira de polietileno $(2 \mathrm{~mm})$. As Tabelas 1 e 2 mostram as características química, física e mineralógica dos solos investigados.

Tabela 1. Características química, física e mineralógica dos solos estudados

\begin{tabular}{lccc}
\hline Característica & Latossolo* & Neossolo & Vertissolo \\
\hline $\mathrm{pH}$ & 4,7 & 6,0 & 6,7 \\
$\mathrm{MO}(\%)$ & $2,3 \pm 0,2$ & $3,6 \pm 0,2$ & $2,0 \pm 0,2$ \\
$\mathrm{Al}\left(10^{-2} \mathrm{~mol} \mathrm{~L}^{-1}\right)$ & $2,2 \pm 0,2$ & $\mathrm{ND}$ & $\mathrm{ND}$ \\
$\mathrm{H}^{+}+\mathrm{Al}\left(10^{-2} \mathrm{~mol} \mathrm{~L}^{-1}\right)$ & $7,8 \pm 0,6$ & $4,8 \pm 0,3$ & $4,1 \pm 0,3$ \\
$\mathrm{Ca}\left(10^{-2} \mathrm{~mol} \mathrm{~L}^{-1}\right)$ & $1,1 \pm 0,1$ & $11,6 \pm 0,6$ & $17,5 \pm 0,7$ \\
$\mathrm{Mg}\left(10^{-2} \mathrm{~mol} \mathrm{~L}^{-1}\right)$ & $0,7 \pm 0,1$ & $4,5 \pm 0,3$ & $9,8 \pm 0,6$ \\
$\mathrm{~K}\left(10^{-2} \mathrm{~mol} \mathrm{~L}^{-1}\right)$ & $0,4 \pm 0,1$ & $0,9 \pm 0,1$ & $0,3 \pm 0,1$ \\
$\mathrm{CTC}\left(\mathrm{cmol} \mathrm{kg}^{-1}\right)$ & $10 \pm 2$ & $21 \pm 4$ & $32 \pm 6$ \\
$\mathrm{Fe}$, total $\left(\mathrm{mg} \mathrm{L}^{-1}\right)$ & $157 \pm 7$ & $211 \pm 8$ & $41 \pm 3$ \\
$\mathrm{Cu}$, total $\left(\mathrm{mg} \mathrm{L}^{-1}\right)$ & $18 \pm 1$ & $38 \pm 2$ & $50 \pm 2$ \\
ASE $\left(\mathrm{m}^{2} \mathrm{~g}^{-1}\right)$ & $97 \pm 12$ & $184 \pm 18$ & $256 \pm 22$ \\
Areia $(\%)$ & $29 \pm 3$ & $29 \pm 3$ & $29 \pm 3$ \\
Silte $(\%)$ & $11 \pm 1$ & $12 \pm 1$ & $13 \pm 1$ \\
Argila $(\%)$ & $60 \pm 6$ & $59 \pm 6$ & $58 \pm 6$ \\
\hline
\end{tabular}

$*$ = latossolo vermelho distroférrico

$\mathrm{n}=$ média de 3 determinações

$\mathrm{ND}=$ não detectado

Tabela 2. Composição percentual das argilas dos solos investigados

\begin{tabular}{lccc}
\hline Composição (\%) & latossolo & neossolo & vertissolo \\
\hline $\mathrm{Fe}_{2} \mathrm{O}_{3}$ & 16 & 14 & 6 \\
Gibbsita & 6 & 6 & 0 \\
Caulinita & 68 & 65 & 54 \\
Argilas (2:1) & 10 & 15 & 40 \\
\hline
\end{tabular}

\section{pH do solo}

A determinação do $\mathrm{pH}$ foi efetuada potenciometricamente em suspensão solo-solução contendo $10 \mathrm{~g}$ do solo e $25 \mathrm{~mL}$ de solução de $\mathrm{CaCl}_{2}$ 0,01 mol L-1, após agitação por $15 \mathrm{~min}$ e repouso por $30 \mathrm{~min}^{18}$.

\section{Determinação da acidez trocável $\left(\mathrm{H}^{+}+\mathrm{Al}^{3+}\right)$ no solo}

Após a determinação do $\mathrm{pH}$ do solo, a mesma solução foi utilizada para a determinação da acidez trocável, após a adição de $5 \mathrm{~mL}$ da solução tampão SMP (Shoemaker, McLean \& Pratt) ${ }^{18}$, com agitação por $20 \mathrm{~min}$ e repouso de $60 \mathrm{~min}$. A leitura do $\mathrm{pH}$ foi feita na suspensão, e os dados obtidos foram convertidos em acidez trocável a partir de valores tabelados.

\section{Determinação da matéria orgânica}

Transferiram-se porções de $1 \mathrm{~g}$ do solo para cada erlenmeyer de $250 \mathrm{~mL}$. Adicionaram-se $10 \mathrm{~mL}$ da solução de $\mathrm{K}_{2} \mathrm{Cr}_{2} \mathrm{O}_{7} 1 \mathrm{~mol} \mathrm{~L}^{-1}$ e
$10 \mathrm{~mL}$ de $\mathrm{H}_{2} \mathrm{SO}_{4}$ concentrado em cada um dos três erlenmeyers. Após a agitação e repouso por $30 \mathrm{~min}$, adicionaram-se $50 \mathrm{~mL}$ de $\mathrm{H}_{2} \mathrm{O}$ deionizada, $3 \mathrm{~mL}$ de $\mathrm{H}_{3} \mathrm{PO}_{4}$ concentrado e $0,5 \mathrm{~mL}$ de solução indicadora de difenilamina a $1 \%(\mathrm{~m} / \mathrm{v})$. Titulou-se com solução de $\mathrm{Fe}\left(\mathrm{NH}_{4}\right)_{2}\left(\mathrm{SO}_{4}\right)_{2} \cdot 6 \mathrm{H}_{2} \mathrm{O} 1 \mathrm{~mol} \mathrm{~L}^{-1}$ e utilizou-se o fator 1,724 para a obtenção dos percentuais da matéria orgânica do solo ${ }^{19}$.

\section{Determinações de cálcio e magnésio}

Transferiram-se $5 \mathrm{~g}$ do solo para um erlenmeyer de $125 \mathrm{~mL}$ e adicionaram-se $50 \mathrm{~mL}$ da solução de $\mathrm{KCl} 1 \mathrm{~mol} \mathrm{~L}^{-1}$, agitando-se por 15 min e deixando em repouso por $12 \mathrm{~h}$. Para a determinação do $\mathrm{Mg}$, transferiu-se $1 \mathrm{~mL}$ do sobrenadante para outro recipiente, adicionaram-se $25 \mathrm{~mL}$ de água deionizada e $1,5 \mathrm{~mL}$ de solução de $\mathrm{La} 100 \mu \mathrm{g} \mathrm{L}^{-1}$. Para a determinação do Ca, transferiu-se $1 \mathrm{~mL}$ do sobrenadante para outro recipiente, adicionaram-se $25 \mathrm{~mL}$ de $\mathrm{H}_{2} \mathrm{O}$ e $2 \mathrm{~mL}$ de solução de $\mathrm{KCl}$ 1,3 mol L-1. As determinações de $\mathrm{Mg}$ e $\mathrm{Ca}$ foram feitas em espectrofotômetro de absorção atômica da Varian, modelo Spectr AA 10 Plus, em chama acetileno-óxido nitroso, e as seguintes condições: $\lambda=422,7 \mathrm{~nm}$ e fenda $=0,5 \mathrm{~nm}$ para o $\mathrm{Ca} ; \lambda=285,2 \mathrm{~nm}$ e fenda $=0,5 \mathrm{~nm}$ para $\mathrm{o} \mathrm{Mg}$.

\section{Determinação de potássio através da solução extratora Mehlich 1}

Transferiram-se $10 \mathrm{~g}$ do solo para um erlenmeyer de $125 \mathrm{~mL}$ e adicionaram-se $50 \mathrm{~mL}$ da solução de Mehlich $1(\mathrm{HCl} \mathrm{0,05} \mathrm{mol} \mathrm{L}-1$ e $\left.\mathrm{H}_{2} \mathrm{SO}_{4} 0,0125 \mathrm{mo} \mathrm{L}^{-1}\right)^{20}$. Agitou-se por $5 \mathrm{~min}$ e deixou-se em repouso por $12 \mathrm{~h}$. Transferiu-se $1 \mathrm{~mL}$ do sobrenadante para outro recipiente e adicionaram-se $25 \mathrm{~mL}$ de $\mathrm{H}_{2} \mathrm{O}$ e $2 \mathrm{~mL}$ da solução de $\mathrm{CsNO}_{3}$ contendo $100 \mu \mathrm{g} \mathrm{L}^{-1}$ de césio. A determinação do $\mathrm{K}$ foi feita por EAA, chama ar:acetileno, $\lambda=766,5 \mathrm{~nm}$ e fenda de $0,5 \mathrm{~nm}$.

\section{Capacidade de troca catiônica (CTC)}

A CTC do solo foi calculada pela soma dos cátions trocáveis $\left(\mathrm{Ca}^{2+}, \mathrm{Mg}^{2+}, \mathrm{K}^{+}\right)$e a acidez trocável $\left(\mathrm{H}^{+}+\mathrm{Al}^{3+}\right)$ segundo metodologias adotadas pela EMBRAPA ${ }^{20}$ e IAPAR apud Sodré $^{18}$.

\section{Área superficial específica (ASE)}

A determinação da ASE foi feita pelo método indireto de adsorção do éter monoetílico do etileno glicol (EMEG). Este método baseia-se na retenção por adsorção do EMEG na superfície do sólido. Submetendose à evaporação, esta diminui quando não mais existe EMEG livre, restando somente o adsorvido formando uma camada monomolecular. A concentração de EMEG existente é proporcional à superfície do sólido. Nestas condições, a cada 0,2860 kg de EMEG corresponde a uma camada monomolecular de um metro quadrado de argila ${ }^{20}$.

\section{Determinação da textura e fracionamento do solo}

A determinação da textura do solo e a sua classificação granulométrica foram feitas segundo a metodologia de Suguio ${ }^{21}$ e realizada nos laboratórios de Pedologia e Sedimentologia da Universidade Estadual de Maringá. Para os estudos de fracionamento do solo, as amostras foram pesadas em frascos de polietileno de 2 $\mathrm{L}$, adicionaram-se $250 \mathrm{~mL}$ de $\mathrm{H}_{2} \mathrm{O}$ e $40 \mathrm{~mL}$ de $\mathrm{NaOH} 1 \mathrm{~mol} \mathrm{~L}^{-1}$, com agitação por $3 \mathrm{~h}$, completando-se o volume com água deionizada, para a sua decantação. A fração argila com $<2 \mu \mathrm{m}$ foi separada por sifonamento a $10 \mathrm{~cm}$ de profundidade dos frascos a cada 24 h, e após cada sifonamento completou-se o volume com água deionizada, com agitação do frasco para a decantação do silte e areia. O ciclo de sifonamento foi repetido por 12 vezes. 
As frações das argilas sifonadas foram transferidas a outros frascos e floculadas com soluções de $\mathrm{MgCl}_{2} 1 \mathrm{~mol} \mathrm{~L}^{-1}$. Lavou-se a argila com água deionizada para a eliminação do excesso do sal e secou-se em estufa a $60 \pm 5^{\circ} \mathrm{C}$. Os residuais de areia e silte + argila foram separados em peneiras de 270 mesh.

\section{Análise mineralógica}

As alterações de massas provocadas pelo aquecimento da caulinita e gibbsita foram obtidas a partir de análise termogravimétrica (TGA), que perdem moléculas de água e outras substâncias voláteis em temperaturas distintas de aquecimento, contribuindo assim para as suas identificações. As análises das frações residuais dos três tipos de solos foram conduzidas no TGA modelo TA-50-Shimadzu, em cadinhos de platina para o acondicionamento das amostras.

\section{Extração seqüencial}

As quatro fases geoquímicas foram investigadas na seguinte ordem: óxido de ferro amorfo, óxido de ferro cristalino, orgânica e residual, com algumas modificações em relação ao método proposto por Thomas et $\mathrm{al}^{17}$. A Figura 1 mostra o fluxograma das etapas de extrações nas frações geoquímicas dos solos investigados.

Os experimentos, em triplicatas, foram iniciados com 1,80 \pm 0,01 g do solo seco, utilizando-se um agitador magnético para a homogeneização da amostra e a solução do extrator inicial. A seguir, a filtração foi realizada à vácuo com membranas Millipore de $0,45 \mu \mathrm{m}$, lavando-se as membranas com água destilada. Na seqüência, as extrações foram realizadas da mesma forma para as demais

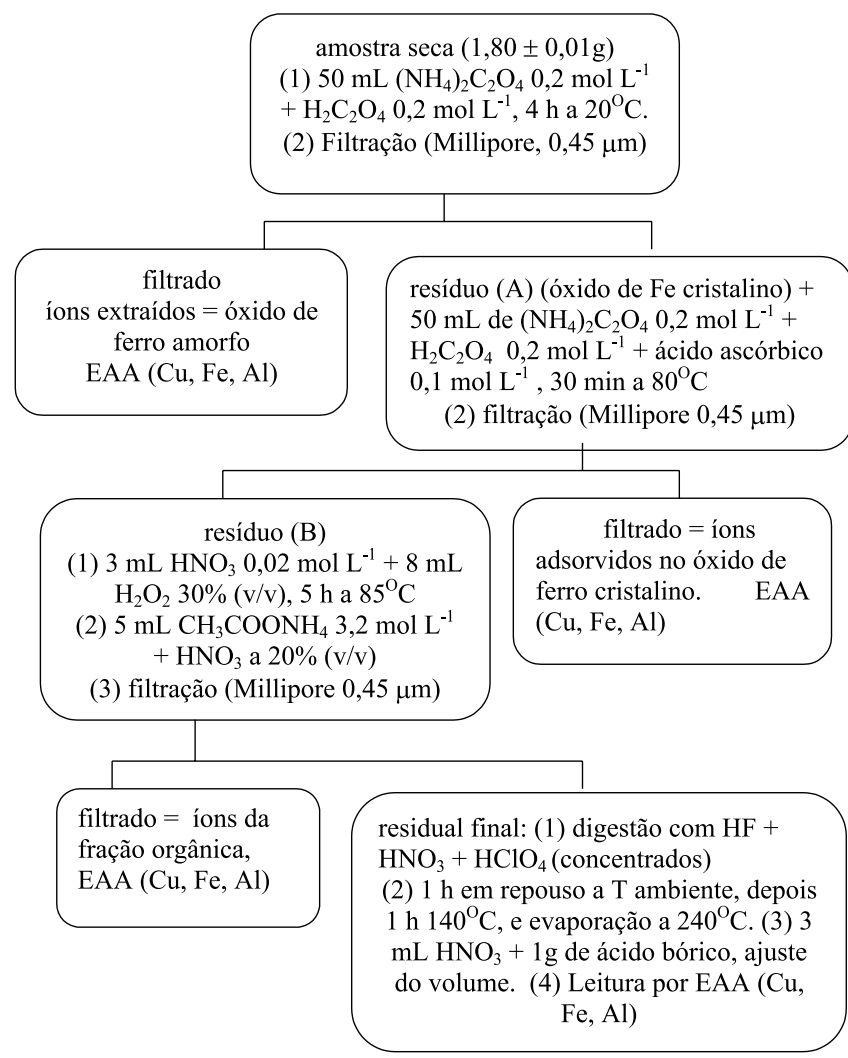

Figura 1. Fluxograma das etapas das extrações seqüenciais das frações geoquímicas. As determinações de $\mathrm{Cu}$, Fe e Al foram feitas por espectrofotometria de absorção atômica (EAA) fases acima citadas. Após as separações, os resíduos parciais foram secos em estufa a $60{ }^{\circ} \mathrm{C}$ durante $12 \mathrm{~h}$. A primeira etapa da extração (óxido de $\mathrm{Fe}$ amorfo) foi realizada em tubos de vidro, com agitação magnética contínua para aumentar a interação entre o reagente e a argila. Os extratos e os resíduos foram separados por filtração à vácuo com membranas Millipore de 0,45 $\mu \mathrm{m}$. Durante as filtrações, os resíduos foram lavados com água deionizada, secos em estufa a $60 \pm 5{ }^{\circ} \mathrm{C}$, pesados e encaminhados para a etapa seguinte. Nestas etapas, as extrações dos metais das frações de óxido de $\mathrm{Fe}$ cristalino e da matéria orgânica, foram feitas a 80 e $85^{\circ} \mathrm{C}$, com agitação magnética contínua, em banho termostatizado, conforme o esquema da Figura 2.

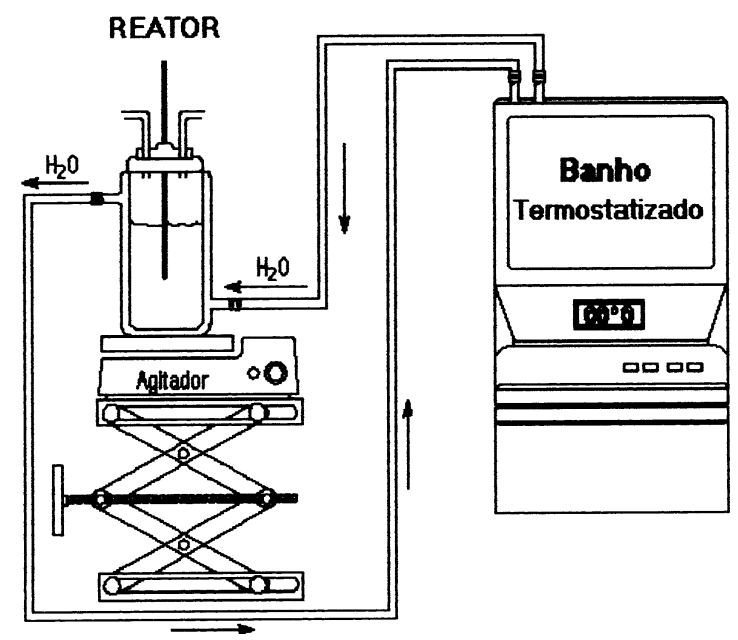

Figura 2. Sistema com o reator e banho termostatizado utilizado nas extrações seqüenciais

Nas digestões dos resíduos foram utilizadas cerca de 0,10 a $0,20 \pm$ $0,01 \mathrm{~g}$ de cada amostra em tubos de teflon, adicionando-se $4 \mathrm{~mL}$ de $\mathrm{HNO}_{3}, 1 \mathrm{~mL}$ de $\mathrm{HClO}_{4}$ e $4 \mathrm{~mL}$ de $\mathrm{HF}$ concentrados. Decorridos cerca de $1 \mathrm{~h}$ à temperatura ambiente, as amostras foram aquecidas a $140 \pm 5$ ${ }^{\circ} \mathrm{C}$ por $1 \mathrm{~h}$ e, a seguir, a $240 \pm 10{ }^{\circ} \mathrm{C}$, sendo evaporadas até um volume final de aproximadamente $2 \mathrm{~mL}$. Após o resfriamento, adicionaram-se $3 \mathrm{~mL}$ de $\mathrm{HNO}_{3}$ concentrado, $1 \mathrm{~g}$ de ácido bórico em $50 \mathrm{~mL}$ de água destilada, completando-se o volume com água destilada a $100 \mathrm{~mL}$ em balão volumétrico. A seguir, as determinações de $\mathrm{Cu}, \mathrm{Fe}$ e $\mathrm{Al}$ foram realizadas por espectrofotometria de absorção atômica.

\section{Determinação de $\mathrm{Cu}, \mathrm{Fe}$ e $\mathrm{Al}$}

As determinações analíticas do $\mathrm{Fe}$ e $\mathrm{Cu}$ foram realizadas em espectrômetro de absorção atômica da Varian, modelo SpectrAA 10 Plus, $\lambda=372,0 \mathrm{~nm}$, e fenda $=0,2 \mathrm{~nm}$ para o ferro, e em $\lambda=324,8 \mathrm{~nm}$ e fenda $=0,2 \mathrm{~nm}$ para o $\mathrm{Cu}$. Na determinação do alumínio no espectrofotômetro CGAA $7000 \mathrm{ABC}$, de duplo feixe, as condições de análise foram as seguintes: $\lambda=396,2 \mathrm{~nm}$, fenda $=0,5 \mathrm{~nm}$, em chama acetileno-óxido nitroso.

\section{RESULTADOS E DISCUSSÃO}

Conforme se observa nas Tabelas 1 e 2, os solos investigados apresentam características bem distintas e a mineralogia da fração argila é relativamente simples, onde poucos minerais correspondem a mais de $95 \%$ da mesma. A caulinita é o mineral que perfaz a maior parte da fração argila desses solos tropicais, seguido pelos óxidos e hidróxidos de $\mathrm{Fe}$ e $\mathrm{Al}$ e, em quantidades menores, os minerais do 
tipo 2:1 (vermiculita). Os solos apresentam características argilosas, com baixos teores de areia e silte, e matéria orgânica variando de 2,0 a 3,6\%. Por exemplo, para o latossolo vermelho distroférrico, a composição é de $29 \%$ de areia, $11 \%$ de silte e $60 \%$ de argila. Por outro lado, a fração argila deste solo é constituída de $16 \%$ de $\mathrm{Fe}_{2} \mathrm{O}_{3}$ (amorfo e cristalino), $6 \%$ de gibbsita, $68 \%$ de caulinita e $10 \%$ de vermiculita, perfazendo o total de $100 \%$.

Os resultados obtidos em relação à caulinita são comparáveis aos relatados para amostras de solos da região do "Triângulo Mineiro" em Minas Gerais, Brasil ${ }^{22}$, mas diferem consideravelmente em relação à gibbsita e vermiculita. Os valores encontrados para a ASE nos solos pelo método do EMEG, para o latossolo vermelho distroférrico, neossolo e vertissolo $\left(97 \pm 12,184 \pm 18\right.$ e $\left.256 \pm 22 \mathrm{~m}^{2} \mathrm{~g}^{-1}\right)$ são significativamente mais elevados que os encontrados nos solos acima citados, e determinados pelo método da adsorção do nitrogê-

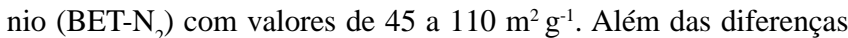
nas características dos solos, os resultados para as áreas superficiais específicas pelo método do EMEG geralmente fornecem valores mais elevados que o método do BET- $\mathrm{N}_{2}$ para as mesmas amostras de so$\operatorname{los}^{23}$.

Os latossolos investigados possuem características físicas de alta porosidade, baixa densidade global e estrutura granular muito estável. Sua mineralogia é dominada por óxidos de Fe, caulinita e gibbsita. Provavelmente, a associação dos óxidos de Fe com a caulinita e, algumas vezes, com a gibbsita, formam agregados muito estáveis que se comportam como partículas de areia ${ }^{22}$. O neossolo e vertissolo desenvolvidos em regiões de relevos acidentados na presença de lençóis freáticos, são descritos como solos mais jovens por serem menos intemperizados e apresentaram quantidades crescentes de minerais de argila 2:1. O vertissolo possui a maior concentração de minerais 2:1, e menores concentrações dos óxidos de ferro e caulinita.

As curvas de TGA (curvas superiores) e TGA diferencial (curvas inferiores) dos resíduos dos três solos investigados, após as extrações com oxalato de amônio e ácido ascórbico, são mostradas na Figura 3. Os picos máximos das desidroxilações da gibbsita e caulinita ocorrem em 250 e $450{ }^{\circ} \mathrm{C}$, respectivamente. Observa-se, portanto, a presença dos dois minerais nas referidas temperaturas para o latossolo vermelho distroférrico e neossolo e a ausência da gibbsita no vertissolo. Observa-se também na curva de TGA diferencial uma maior variação para o vertissolo em temperatura até $100{ }^{\circ} \mathrm{C}$ em decorrência da evaporação da água. As quantificações dos minerais nas fases residuais finais foram desenvolvidas através de cálculos estequiométricos a partir das reações de desidratações dos mesmos. Os valores em percentagens encontrados para a gibbsita e caulinita nos três tipos de solos foram respectivamente, latossolo vermelho distroférrico: gibbsita (3) e caulinita (45), neossolo: gibbsita $(2,3)$ e caulinita (55) e vertissolo: gibbsita (10) e caulinita (37). Observouse, portanto, uma elevada razão caulinita/gibbsita para o neossolo e o latossolo e uma baixa razão para o vertissolo.

A solução ácida de oxalato de amônio $0,2 \mathrm{~mol} \mathrm{~L}^{-1}$ a $20{ }^{\circ} \mathrm{C}$ extrai o óxido de $\mathrm{Fe}$ amorfo, o qual não possui estrutura cristalina definida, e os demais cátions trocáveis ou fitodisponíveis. A solução ácida de oxalato de amônio, conjuntamente com o ácido ascórbico, reduzem e dissolvem os óxidos de Fe cristalinos, tais como a goetita e hematita, com a liberação dos cátions adsorvidos em suas superfícies. A Figura 4 mostra os percentuais de $\mathrm{Fe}, \mathrm{Al} \mathrm{e} \mathrm{Cu}$ em relação à soma das concentrações, nas frações de óxidos de ferro amorfo, cristalino, matéria orgânica e residual dos solos investigados. Mostra ainda que a maior concentração de Fe no latossolo vermelho distroférrico e neossolo encontram-se na fração de óxido de Fe cristalino. Por outro lado, as maiores concentrações de Fe no vertissolo encontram-se na fração residual, sendo que este solo possui um alto percentual de minerais do tipo 2:1. Observou-se também, na Figura 4, que os

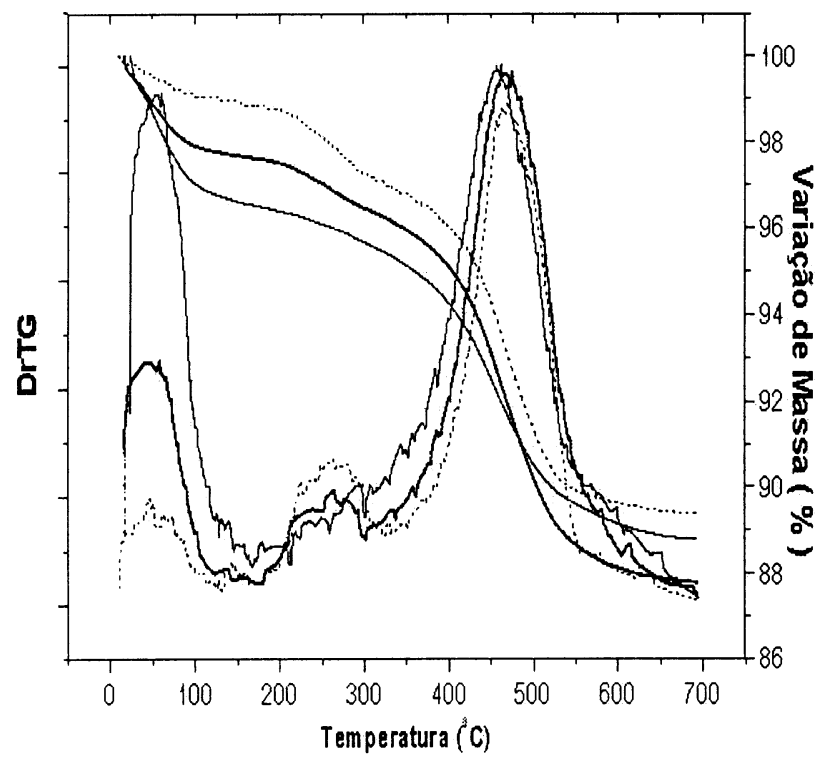

Figura 3. Análise termogravimétrica-TGA (curvas superiores) e análise térmica diferencial (curvas inferiores) da amostra da fração residual após o tratamento com a solução ácida de oxalato de amônio e ácido ascórbico. Lato $(. . . . . .)=$. latossolo vermelho distroférrico

Neo $(. . .)=$. neossolo

$\operatorname{Vert}(-)$ vertissolo

Nas curvas superiores, a terceira curva corresponde ao vertissolo e, nas curvas inferiores, a curva mais intensa entre 0 e $100^{\circ} \mathrm{C}$ corresponde também ao vertissolo

\section{(\%) de Fe extraído (colunas à esquerda, Al (centro) e Cu direita)}

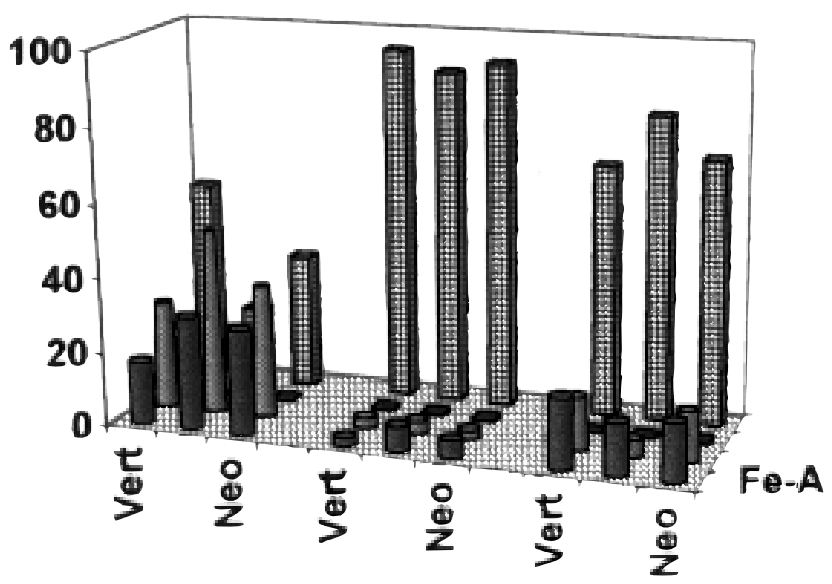

Figura 4. Percentagens de Fe (colunas à esquerda), Al (centro) e Cu (direita) em relação à soma das concentrações, nas quatro frações geoquímicas nos três tipos de solos. Óxido de ferro amorfo $=\mathrm{Fe}$-A; óxido de ferro cristalino $=F e-C ;$ matéria orgânica $=M O ;$ Res. $=$ residual. Na figura, observa-se apenas a legenda para o $\mathrm{Fe}$-A no primeiro plano, porém, a sequência é a seguinte: $\mathrm{Fe}-\mathrm{A}, \mathrm{Fe}-\mathrm{C}, \mathrm{MO}$ e residual respectivamente. Vert = vertissolo, Lato = latossolo vermelho distroférrico, que se localiza entre as colunas do Vert e Neo, onde Neo = neossolo 
extratores utilizados não foram eficientes para a extração do Al. As diferenças observadas nas razões caulinita/gibbsita foram confirmadas pela menor extração do $\mathrm{Al}$ no vertissolo em relação ao neossolo e o latossolo, nos óxidos de $\mathrm{Fe}$ amorfo e cristalino. Cerca de $90 \%$ do $\mathrm{Al}$ aparecem na fração residual do latossolo e o neossolo, e mais de $95 \%$ no vertissolo. O Al além de ser fitotóxico, induz a deficiência do cálcio em plantas e animais, provoca problemas renais em seres humanos, sendo ainda um dos prováveis responsáveis pelo mal de Alzheimer, cujas pessoas portadoras apresentam elevados níveis deste elemento no cérebro ${ }^{24}$. No entanto, por não se encontrar disponível para a absorção pelas plantas, a sua toxicidade é reduzida. A inexistência de estudos sobre extrações seqüenciais e especiação química do $\mathrm{Al}$ em solos tropicais, torna praticamente impossível uma comparação com os resultados obtidos.

A Tabela 3 mostra as concentrações de $\mathrm{Cu}$ nas frações geoquímicas, e as maiores concentrações deste elemento foram encontradas nos óxidos de Fe amorfo, cristalino e residual. Vários autores tem demonstrado, no entanto, a preferência do cobre em se ligar a fração orgânica ${ }^{11,15,25,26}$. Outros, no entanto, tem encontrado concentrações muito elevadas na fração residual, e valores muito baixos para as outras frações e, em alguns casos, abaixo do limite de detecção para as fases trocáveis, carbonatos e matéria orgânica ${ }^{27}$.

Tabela 3. Concentração do cobre em $\mu \mathrm{g} \mathrm{g}^{-1}, \operatorname{com} \mathrm{n}=3$ determinações e os respectivos desvios-padrão, nas 4 frações geoquímicas: óxido de ferro amorfo, óxido de ferro cristalino, matéria orgânica e residual

\begin{tabular}{lcccl}
\hline Solos & OxFe-amorfo & OxFe-cristalino & MO & Residual \\
\hline Latossolo & $35 \pm 2$ & $26 \pm 2$ & $4,0 \pm 0,2$ & $344 \pm 16$ \\
Neossolo & $58 \pm 3$ & $158 \pm 8$ & $7,0 \pm 0,8$ & $384 \pm 16$ \\
Vertissolo & $68 \pm 3$ & $87 \pm 5$ & $0,5 \pm 0,1$ & $152 \pm 8$ \\
\hline
\end{tabular}

\section{CONCLUSÕES}

Na extração seqüencial, observou-se que o maior percentual do Al permaneceu na fração residual, especialmente no vertissolo (>95\%). A elevada razão caulinita/gibbsita no latossolo e neossolo em relação à baixa razão no vertissolo, foi confirmada pela menor extração do $\mathrm{Al}$ do vertissolo nas etapas preliminares. Estes fatos mostram a pouca fitodisponibilidade do $\mathrm{Al}$, ou também, a pouca eficiência e especificidade dos extratores utilizados. Por outro lado, a extração seqüencial foi eficiente nas extrações do $\mathrm{Fe}$ e $\mathrm{Cu}$, e os resultados foram compatíveis com os encontrados em outras investigações.

\section{REFERÊNCIAS}

1. Dixon, J. B.; Weed, B.; Minerals in Soil Environments, $2^{\text {nd }}$ ed., Madison University Press: Madison, 1989, p. 279.

2. Sposito, G.; The Chemistry of Soils, Oxford University Press: New York. 1989, p. 290.

3. Trivedi, P.; Axe, L.; J. Colloid Interface Sci. 1999, 218, 554.

4. Muniz, L. L. F.; Jordão, C. P.; Brune, W.; Pereira, J.P.; Reis, E.L.; Quim. Nova 1996, 19, 464.

5. Kabata-Pendias, A.; Pendias, H.; Trace Elements in Soils and Plants, Boca Raton: CRC Press, 1992, p. 365.

6. MacBride, M. B.; Sauve, S.; Hendershot, W.; Eur. J. Soil Sci. 1997, 48, 379.

7. MacBride, M.B.; Environmental Chemistry of Soils, Oxford University Press: New York, 1994, p. 416.

8. Couturas, S.; Bourgeois, S.; Bermond, A.; Environ. Technol. 2000, 21, 77.

9. Miller, W. P.; Martens, D. C.; Zelazny, L. W.; Soil Sci. Soc. Am. J. 1986, $50,598$.

10. Wilcke, W.; Kretzschmar, S.; Bundt, M.; Saborio, G.; Zech, W.; Soil Sci. 1998, 163, 463 .

11. Abdelsaheb, I.; Schwab, P.; Banks, M. K.; Hetrick, B.A.; Water, Air, Soil Pollut. 1994, 1-2, 73.

12. Campos, E.; Barahona, E.; Lahica, M.; Mingorance, M. D.; Anal. Chim. Acta 1998, 369, 235.

13. Matos, A. T.; Fontes, M. P. F.; Jordão, C. P.; Costa, L. M.; Rev. Bras. Ciência Solo 1990, 20, 379.

14. Gomes, P. C.; Fontes, M. P. F.; Costa, L. M.; Mendonça, E.; Rev. Bras. Ciência Solo 1997, 21, 543.

15. Tessier, A.; Campbell, P. G. C.; Bissom, M.; Anal. Chem. 1979, 51, 844

16. Ma, Y. B.; Uren, N. C.; Geoderma 1998, 84, 157.

17. Thomas, R. P.; Ure, A. M.; Davidson, C. M.; Littlejohn, D.; Rauret, G.; Rubio, R.; López-Sánchez, J. F.; Anal. Chim. Acta 1994, 286, 423.

18. Sodré, F. F.; Lenzi, E.; Costa, A. C. S.; Quim. Nova 2001, 24, 324.

19. Gallez, A.; Juo, A. S. R.; Herbillon, A. J.; Soil Sci. Soc. Am. J. 1976, 40, 601.

20. Claessen, M. C. E.; Barreto, W. O.; Paula, J. L.; Duarte, M. N.; Manual de Métodos de Análise de Solo, EMBRAPA-CNS: Rio de Janeiro, 1997, p. 212.

21. Suguio, K.; Introdução à Sedimentologia, Edgard Blucher: São Paulo, 1973, p. 317.

22. Fontes, M. P. F.; Clays Clay Miner. 1992, 40, 175.

23. Fontes, M. P. F.; Weed, S.B.; Geoderma 1996, 72, 37.

24. Fifield, F. W.; Haines, P. J.; Environmental Analytical Chemistry, $2^{\text {nd }}$ ed., Blackwell Science: London, 2000, p. 490.

25. Leyeyter, L.; Probst, J.; Int. J. Environ. Anal. Chem. 1999, 73, 109.

26. Urasa, I. T.; Macha, S. F.; Int. J. Environ. Anal. Chem. 1996, 64, 81.

27. Morera, M. T.; Echeverría, J. C.; Mazkiarán, C.; Garrido, J. J.; Environ. Pollut. 2001, 113, 135. 